\title{
“O segredo é a oralidade": práticas educativas na Irmandade da Boa Morte
}

"The secret is orality": educational practices in the Irmandade da Boa Morte

"El secreto es la oralidade": prácticas educativas en la Irmandade da Boa Morte

SOlyANE SILVEIRA LIMA (D)a

\section{Resumo}

O presente artigo tem como objetivo analisar as práticas educativas na Irmandade da Boa Morte a partir do uso da história oral, problematizando questões relativas ao comportamento e a conduta das irmãs mais antigas em relação as mais novas, no tocante a transmissão dos costumes. O interesse pela educação de mulheres na Irmandade surgiu a partir da observação da existência de poucos trabalhos sobre essa temática, especialmente, por ser uma forma de educação que não acontece no ambiente escolar, mas dentro das tradições e costumes de uma instituição religiosa. Estabelecendo-se assim, um elo entre gênero, educação e religião. Utilizou-se o conceito de práticas educativas, nesse caso, não escolares. E se estabeleceu questionamentos entre às relações de poder e de status, bem como, entre as tensões que estas engendram. Quanto ao procedimento metodológico, utilizou-se a história oral. O texto foi organizado em três seções, além da introdução e das considerações finais. Na primeira, discutiu-se sobre o significado das irmandades e a educação que acontece no seu interior. Em seguida, discorreu-se sobre a Irmandade da Boa Morte. E, por fim, a partir das entrevistas realizadas, analisaram-se as práticas educativas nessa instituição, verificando a presença de uma educação alicerçada na hierarquia, na disciplina e difundida através das gerações.

Palavras-chave: Práticas Educativas. Irmandade da Boa Morte. História Oral.

\footnotetext{
a Universidade Federal do Recôncavo da Bahia (UFRB), Cachoeira, BA, Brasil. Doutora em Educação, e-mail: solyanesl@gmail.com
} 


\begin{abstract}
This article aims to analyze educational practices in the Irmandade da Boa Morte from the use of oral history, problematizing questions concerning the behavior and conduct of the older sisters in relation to the younger ones, regarding the transmission of customs. The interest in the education of women in the Brotherhood arose from the observation of the existence of few works on this theme, especially because it is a form of education that does not happen in the school environment, but within the traditions and customs of a religious institution. Thus establishing a link between gender, education and religion. We used the concept of educational practices, in this case, non-school. And questions have been established between the relations of power and status, as well as between the tensions they engender. As for the methodological procedure, the oral history was used. The text was organized in three sections, besides the introduction and the final considerations. The first discussed the meaning of brotherhoods and the education that takes place within them. Then it was discussed about the Irmandade da Boa Morte. And finally, from the interviews conducted, the educational practices in this institution were analyzed, verifying the presence of an education based on hierarchy, discipline and spread through the generations.
\end{abstract}

Keywords: Educational Practices. Irmandade da Boa Morte. Oral History.

\title{
Resumen
}

Este artículo tiene como objetivo analizar las prácticas educativas en la Irmandade da Boa Morte a partir del uso de la historia oral, problematizando cuestiones relacionadas con el comportamiento y la conducta de las hermanas mayores en relación con las más jóvenes, en relación con la transmisión de costumbres. El interés en la educación de las mujeres en la Hermandad surgió de la observación de la existencia de pocas obras sobre este tema, especialmente porque es una forma de educación que no ocurre en el ambiente escolar, sino dentro de las tradiciones y costumbres de una institución religiosa. Estableciendo así un vínculo entre género, educación y religión. Utilizamos el concepto de prácticas educativas, en este caso, no escolares. Y se han establecido cuestiones entre las relaciones de poder y estatus, así como entre las tensiones que generan. En cuanto al procedimiento metodológico, se utilizó la historia oral. El texto se organizó en tres secciones, además de la introducción y las consideraciones finales. El primero discutió el significado de las hermandades y la educación que se lleva a cabo dentro de ellas. Luego se discutió sobre la Irmandade da Boa Morte. Y finalmente, a partir de las entrevistas realizadas, se analizaron las prácticas educativas en esta institución, verificando la presencia de una educación basada en la jerarquía, la disciplina y la difusión entre generaciones.

Palabras clave: Prácticas Educativas. Irmandade da Boa Morte. Historia Oral. 


\title{
Introdução
}

“O segredo é a oralidade". É com essa frase que Dona Neneu (2017), integrante da Irmandade da Boa Morte, localizada em Cachoeira/BA, explica a forma como os ensinamentos são passados da geração mais velha para a mais nova. E completa, "como se diz: de mãe pra filha"2.

A fala dessa senhora deixa evidente práticas de educação correntes dentro de uma organização religiosa fundada na Bahia pelo idos do século XVIII que congregava africanos, no interior da qual se teciam laços de solidariedade, e, dentre outras funções, cuidava dos funerais dos seus membros. Porém, segundo Luiz Alberto O. Gonçalves (2000), as irmandades remetem a sólidas associações religiosas criadas pelo estado português com vistas a solucionar duas questões:

\begin{abstract}
A primeira mostra claramente que a coroa portuguesa, quando pressionada a autorizar a construção de irmandades na colônia, viu nisso uma saída para se livrar das cláusulas do contrato que a obrigava a construir igrejas e assegurar o culto no Brasil.

A segunda não deixa dúvida de que as irmandades seriam uma solução que iria ao encontro do racismo dos proprietários de escravos. Constrangidos pela hierarquia eclesiástica a catequizar seus escravos e a introduzi-los no mundo cristão, os escravocratas viram nas irmandades uma ótima oportunidade para separar de uma vez por todas as igrejas dos brancos da igreja dos negros. (GONÇALVES, 2000, p. 332).
\end{abstract}

As irmandades de modo geral aceitavam mulheres, porém, na maioria dos casos elas entravam acompanhadas dos maridos. "As mulheres eram desejadas nas irmandades africanas talvez para aumentar o estreito mercado afetivo dos homens. Elas eram pouco numerosas na comunidade africana, principalmente entre escravos" (REIS, 1991).

A Irmandade da Boa Morte é uma associação coorporativa feminina fundada no século XVIII em Salvador, na Igreja da Barroquinha, onde se reuniam "os nagôs da nação queto" (REIS, 1991). A transferência para a cidade de Cachoeira, no recôncavo baiano, aconteceu por volta de 1820, fixando-se numa residência

\footnotetext{
${ }^{2}$ As entrevistas utilizadas neste artigo foram realizadas pelo historiador Djalma de Jesus Santana em 2017, em razão do seu Trabalho de Conclusão de Curso da graduação, licenciatura em História, na UFRB, intitulado, Memória, Tradição e Oralidade: Aspectos educacionais na Irmandade da Boa Morte, sob minha orientação.
} 
conhecida como Casa Estrela, que pertencia a uma africana de nome Karoxa (MACHADO, 2013). De acordo com as fontes orais, “o Major Madeira de Melo expulsou as negras da instituição”, que por sua vez migraram para Cachoeira e deram continuidade a Irmandade da Boa Morte.

Para este artigo objetivamos analisar as práticas educativas na Irmandade da Boa Morte a partir do uso da história oral, problematizando questões relativas ao comportamento e a conduta das irmãs mais antigas para com as mais novas, no tocante a transmissão dos costumes.

O interesse pela educação de mulheres na Irmandade surgiu a partir da observação da existência de poucos trabalhos sobre essa temática, especialmente por ser uma forma de educação que não se dá no ambiente escolar, mas dentro das tradições e costumes de uma irmandade religiosa. Estabelecendo-se assim um elo entre gênero, educação e religião.

Para essa pesquisa buscou-se subsídios teóricos nas contribuições de Thais Nivia de Lima e Fonseca (2009) no tocante ao conceito de práticas educativas, nesse caso, não escolares. Bem como em Norbert Elias (2000), quanto às relações de poder e de status e as tensões que essas engendram, a partir da obra Estabelecidos e Outsiders, tendo em vista a situação das irmãs de bolsa ${ }^{3}$ na instituição. Refletiu-se sobre as estigmatizações produzidas por essa condição e sobre a associação entre a condição outsider e de anomia ${ }^{4}$ na Irmandade. Quanto ao procedimento metodológico, utilizou-se a história oral, a partir da obra $A$ voz do passado, de Paul Thompson (1992).

Assim, o texto está organizado em três tópicos, para além dessa introdução e das considerações finais. No primeiro discutiu-se sobre o significado das irmandades e qual tipo de educação acontece no seu interior. Em seguida, discorreu-se sobre a Irmandade da Boa Morte. E, por fim, a partir dos depoimentos realizados, analisaram-se as práticas educativas presentes nessa instituição.

\footnotetext{
${ }^{3}$ As irmãs de bolsa são aspirantes a irmãs da Boa Morte, que passam por uma observação de cinco anos, e para serem aceitas precisam aderir ao código de conduta ética da instituição.

${ }^{4}$ De acordo com Elias (2000), na relação entre estabelecidos e outsiders, o grupo estabelecido tende a atribuir ao grupo outsider a característica de grupo inferior, e, pior, associando a situação de anomia (ELIAS, 2000, p. 22).
} 


\section{As Irmandades como lócus de práticas educativas não escolares}

Até o período imperial brasileiro as irmandades foram consideradas como importantes veículos do catolicismo popular. Entretanto suas origens remontam a Europa, a partir das confrarias que atuavam em favor dos seus membros e dos necessitados através do assistencialismo, do culto cristão e da organização de funerais para os que delas participassem. Segundo João José Reis (1991, p. 49), as confrarias se subdividiram em irmandades e ordens terceiras: "As confrarias, divididas principalmente em irmandades e ordens terceiras, existiam em Portugal desde o século XIII pelo menos, dedicando-se a obras de caridade voltadas para seus próprios membros ou para pessoas carentes não associadas”. As ordens terceiras eram dirigidas por religiosos e se associavam as ordens religiosas tradicionais, por exemplo, a franciscana, a dominicana, etc. Fato que lhes proporcionou certo prestígio em relação às irmandades, que eram formadas principalmente por leigos.

O funcionamento das confrarias só era possível se essas fossem acolhidas por uma igreja, ou se construíssem a sua própria. Além de ter seus estatutos, também denominados de compromissos, aprovados pelas autoridades eclesiásticas.

Em geral cada templo acomodava diversas irmandades, que veneravam seus santos patronos em altares laterais. Existiam irmandades com a mesma denominação espalhadas pelas igrejas do Brasil e mesmo de cada província ou cidade.

$[\ldots]$

Muitas irmandades que iniciaram sua carreira de maneira tímida, em altares laterais, com o tempo levantaram recursos para a construção de seus próprios templos. (REIS, 1991, p. 49).

Os estatutos das irmandades regulavam a sua administração, estabeleciam as condições raciais e sociais exigidas para seus membros, além de prever direitos e deveres.

Entre os deveres estavam o bom comportamento e a devoção católica, o pagamento de anuidades, a participação nas cerimônias civis e religiosas das irmandades. Em troca, os irmãos tinham direito à assistência médica e jurídica, ao socorro em momento de crise financeira, em alguns casos ajuda para a compra de alforria e, muito especialmente, 
direito a enterro decente para si e membros da família, com acompanhamento de irmãos e irmãs de confraria, e sepultura na capela da irmandade. (REIS, 1991, p. 50).

As irmandades, portanto, eram associações que implicitamente representavam os diversos grupos sociais. Em seu interior teciam relações fundamentadas em questões econômicas, religiosas e, principalmente, étnico-raciais. Havendo irmandades de brancos, pretos e pardos.

Magnair Santos Barbosa (2011) afirma que alguns estudiosos têm pensado as irmandades no contexto da permissividade aos africanos como forma de concessão. Ou seja, a devoção a um santo católico por africanos como um meio de atração a religião do branco, que resultaria em controle e vigilância sob os comportamentos.

Porém ela defende que essas instituições foram "verdadeira vias de mão dupla". Podendo servir tanto como instrumento moderador das tensões sociais, como uma forma de legitimar aos africanos um cunho institucional na esfera política, para além da religiosa.

Ao participar de práticas católicas, os escravos podiam se projetar para além das fronteiras do trabalho - seja esse exercido num âmbito mais privativo e fechado das senzalas, ou urbano, mais aberto e flexível, onde era possível ainda reunir-se nos cantos. Movimentando-se no mundo dos brancos, os negros catolizados podiam gozar de certa isonomia social, pelo menos no âmbito da representação, na medida em que faziam suas festas, procissões e enterros igualmente suntuosos. (BARBOSA, 2011, p. 31).

As irmandades eram, portanto, uma alternativa de parentesco, tendo em vista que a escravidão e a diáspora dissolveram os laços familiares de sangue. Dessa forma, o catolicismo negro proporcionou a aproximação de seus membros através de laços afetivos. "Cabia a 'família' de irmãos oferecer a seus membros, além de um espaço de comunhão e identidade, socorro nas horas de necessidade, apoio para conquista da alforria, meios de protesto conta os abusos senhoriais e, sobretudo rituais fúnebres dignos” (REIS, 1991, p. 55).

Assim, a hipótese que aventamos é que as irmandades além de funcionarem como meios de afirmação cultural eram instituições nas quais ocorriam práticas educativas. Espaços nos quais os membros mais novos eram educados pelos mais velhos através da oralidade. 
Para comprovar essa hipótese precisamos refletir a respeito de algumas questões: o que é educação? Onde ela ocorre? Quais os tipos? O que são práticas educativas? Qual a relação entre práticas culturais e educativas?

Para Carlo Rodrigues Brandão (2001) há várias formas de educar e vários modelos de educação. Ela existe difusa na sociedade e a escola não é o único lugar onde ela acontece. "A educação pode existir livre e, entre todos, pode ser uma das maneiras que as pessoas criam para tornar comum, como saber, como ideia, como crença, aquilo que é comunitário como bem, como trabalho, como vida" (BRANDÃO, 2001, p. 10).

Ou seja, é através da educação que uma geração transmite a outra sua cultura, tradições, valores éticos e os saberes intelectuais exigidos pela sociedade e pelo meio em que estão inseridas. Por isso, o ensino escolar não é a única maneira de se educar, a escola não é o único lugar para se ensinar e aprender. Educa-se na família, na comunidade, nas organizações religiosas, nos movimentos sociais, etc.

Maria da Glória Gohn (2010), partindo de um conceito amplo de educação, estabelece uma diferenciação entre três processos de formação dos indivíduos como cidadãos, quais sejam: a educação formal, informal e não formal.

Podemos caracterizar a educação formal como aquela desenvolvida nas escolas, com conteúdos previamente demarcados; a educação não formal é aquela que se aprende "no mundo da vida", via processos de compartilhamento de experiências, principalmente em espaços e ações coletivos cotidianos; e a educação informal como aquela na qual os indivíduos aprendem durante seu processo de socialização gerada nas relações e relacionamentos intra e extrafamiliares (amigos, escola, religião, clube, etc.). A informal incorpora valores e culturas próprias, de pertencimento e sentimentos herdados. Os indivíduos pertencem àqueles espaços segundo determinações de origem, raça/etnia, religião etc. são valores que formam as culturas de pertencimento nativas dos indivíduos. Contrariamente, a educação não formal não é nativa, ela é construída por escolhas ou sob certas condicionalidades, há intencionalidades no seu desenvolvimento, o aprendizado não é espontâneo, não é dado por características da natureza, não é algo naturalizado. (GOHN, 2010, p 16).

Sob essa ótica poderíamos afirmar que os processos educativos que se desenvolvem no interior das irmandades podem ser considerados como educação informal, já que os saberes são transmitidos no processo de vivência e socialização através dos laços culturais e demarcados por referências de pertencimento. Porém, neste trabalho, optamos por refletir para além do processo de formação dos sujeitos 
e buscamos o conceito de práticas educativas (FONSECA, 2009), nesse caso, não escolares, que estão presentes no cotidiano e podem acontecer em instituições como Estado, igreja, irmandades ou fora delas.

Para Fonseca (2009, p. 10), as práticas podem ser definidas "como 'maneiras de fazer' cotidianas dos sujeitos históricos, relacionadas social e culturalmente, na construção de seus espaços, suas posições e suas identidades”. Assim, a ideia de práticas educativas aparece subordinada ao conceito de práticas culturais, que implicam no estabelecimento de estratégias para elaboração e execução das práticas, e se define como "ações de grupos ou de indivíduos de diferentes segmentos, relacionadas com as diversas esferas diferenciadas de poder, institucionalizado ou não” (FONSECA, 2009, p. 11).

Tendo em vista esse conceito mais amplo de práticas educativas, podemos afirmar que elas estão presentes nas irmandades, desenvolvem-se partir dos processos realizados pelos atores dessas instituições e fazem parte da formação cultural da sociedade em que estão inseridos.

\section{A Irmandade da Boa Morte (Cachoeira - Bahia)}

Escrever sobre irmandades negras na Bahia implica em um grande desafio, especialmente no que tange as fontes, pois que os documentos internos não foram preservados e muitas vezes nem existiram. No caso da Irmandade da Boa Morte, a informação que temos é que não existe nenhum documento escrito, que toda tradição é passada através da oralidade.

Como afirmamos inicialmente, a Irmandade de Nossa Senhora da Boa Morte foi fundada no século XVIII na cidade de Salvador, na igreja da Barroquinha, onde se reuniam "os nagôs da nação queto" (REIS, 1991, p. 55). Nas primeiras décadas do século XIX ela é expulsa dessa igreja por perseguição ao candomblé, e se dirige ao Recôncavo onde funda a irmandade em Cachoeira.

A oralidade tende a afirmar terem saído da Igreja da Barroquinha, importante reduto africano na década de 1820, as fundadoras da irmandade da Boa Morte em Cachoeira, de onde, também, saíram as fundadoras das matrizes dos terreiros de candomblés ketu de Salvador. [...] 
"O que eu sei é [...] que tinha essa que era lá na Barroquinha, na frente tinha a igreja, atrás tinha o candomblé [...] foi escorraçada de lá por isso, o candomblé era, como é, perseguido [...] quando veio e saiu todo mundo pro Recôncavo e se tinha muito se espalhou por aí né? quando chegou aqui em Cachoeira não ficaram tantas assim não, porque eu acredito que ficaram irmãs em Santo Amaro, em por aí tudo né? umas continuaram e outras esqueceram, morreram." (BARBOSA, 2011, p. 46).

Cachoeira nesse período gozava de grande relevância na província. Foi um dos primeiros núcleos civilizados do território baiano. Por causa do desenvolvimento do povoado, em 1696 foi criada a freguesia de Nossa Senhora do Rosário da Cachoeira e depois foi elevada a vila, com o nome de Nossa Senhora do Rosário do Porto da Cachoeira ${ }^{5}$. Destacava-se na produção de cana-de-açúcar e tabaco, o que provocou o aumento da população escravizada e com ela a presença de aspectos da sua cultura, religião, dança, culinária, etc. Além de ser um importante entreposto comercial que ligava o sertão a cidade de Salvador ${ }^{6}$.

A cidade de Cachoeira sobre o Paraguaçu é tão poderosa e importante para o comércio da Bahia, que, embora pequena e apertada na margem do seu rio, tem que ser considerada como parte essencial de todo o comércio baiano, merecendo a visita de todo viajante. (AVÉ-LALLEMANT, 1961, p. 56).

Formada apenas por mulheres, a Irmandade da Boa Morte se constituiu em uma forma de resistência a sociedade patriarcal da época, em um meio de preservação da cultura africana e como local de solidariedade entre negras no século XIX.

Segundo Barbosa (2011), ao chegar a Cachoeira a irmandade da Boa Morte se instalou na casa de número 41, na Rua da Matriz ${ }^{7}$, chamada de Casa Estrela ${ }^{8}$, por ter em sua calçada uma estrela em granito. Acredita-se que o cerne da irmandade esteja nesse local, já que ela continua sendo um ponto de referência para as irmãs. Fato observado quando, nas procissões, param em frente à casa para reverenciá-la.

5 Para mais informações consultar a Enciclopédia dos Municípios do IBGE em https://biblioteca.ibge.gov.br/visualizacao/dtbs/bahia/cachoeira.pdf

${ }^{6}$ Cachoeira também se destacou como núcleo das lutas armadas em prol da Independência do Brasil. Para mais informações consultar: Guerra Filho (2004).

${ }^{7}$ Atualmente Rua Ana Nery.

${ }^{8}$ Para mais informações sobre o significado dessa casa, consultar Barbosa (2011, p. 48-49). 
A Casa Estrela, uma casa emblemática leva pesquisadores a elaborarem uma teia de significados a estrela assentada em seu passeio. Parés (2007, p. 184), indica que Ludovina Pessoa, influente líder religiosa em Cachoeira e irmã da Boa Morte, morou na casa Estrela e plantou um assento na sua porta de entrada com a forma de uma estrela de cinco pontas para Legba, considerado como Exu, ele é o principio dinâmico do universo, dono dos caminhos, o mensageiro entre os homens e os deuses e que repassou os segredos da adivinhação aos seres humanos. Assentos são materiais sacralizados relativamente fixos, tidos como residência de divindades. (MACHADO, 2013, p. 42).

Para fazer parte da irmandade, a aspirante a irmã de bolsa ${ }^{9}$ deve ser indicada por uma das irmãs, por parente, pela mãe ou se apresentar voluntariamente demonstrando interesse, ser negra, ter no mínimo 40 anos, fazer parte de religião de matriz africana, cultuar Nossa Senhora da Boa Morte e ter boa conduta, conforme nos relata a irmã Neci Santos Leite (Dona Neneu): “Todas [irmãs] fazem parte de religião de matriz africana [...]. Não pode ter uma vida social vulgar e entram a partir de 40 anos. Você entra aos quarenta, como noviça e aos quarenta e cinco recebe a beca. Passando por uma total avaliação” (DONA NENEU, 2017).

Machado (2013) apresenta uma explicação para essa questão da idade,

Na maioria das entrevistas feita com as irmãs, a questão da idade tem uma justificativa unânime, a mulher acima dos quarenta anos não apresenta mais aqueles "calores da mocidade", é mais madura, tem responsabilidade, tem o tempo livre para se dedicar a devoção. Tenho uma hipótese de que a idade de entrada tem haver com a experiência adquirida na religião do candomblé, e também com a descrição em zelar pelos segredos que lhe são revelados no processo de iniciação. (MACHADO, 2013, p. 45).

Apesar dessa colocação sobre a idade das aspirantes a irmãs de bolsa, precisamos refletir a respeito das relações de poder e status no interior da Irmandade e presentes na fala da entrevistada (Dona Neneu). A relação entre as irmãs mais antigas e as noviças demonstra claramente um padrão de desigualdade entre o grupo estabelecido e o outsider (ELIAS, 2000), onde o grupo mais antigo se vê como melhor e superior, provocando no outro grupo o sentimento de inferioridade.

\footnotetext{
${ }^{9}$ Uma espécie de noviça, como já explicado anteriormente.
} 
É a auto-imagem normal dos grupos que, em termos do seu diferencial de poder, são seguramente superiores a outros grupos interdependentes. Que se trate de quadros sociais, como os senhores feudais em relação aos vilões, os "brancos" em relação aos "negros", os gentios em relação aos judeus, os protestantes em relação aos católicos e vice-versa, os homens em relação as mulheres (antigamente), os Estados nacionais grandes e poderosos em relação a seus homólogos pequenos e relativamente impotentes, quer como no caso de Winston Parva, de uma povoação da classe trabalhadora, estabelecida desde longa data, em relação aos membros de uma nova povoação de trabalhadores em sua vizinhança, os grupos mais poderosos, na totalidade desses casos, veem-se como pessoas melhores, dotadas de uma espécie de carisma grupal, de uma virtude específica que é compartilhada por todos os seus membros e que falta aos outros. Mais ainda, em todos esses casos, os indivíduos "superiores" podem fazer com que os próprios indivíduos inferiores se sintam, eles mesmos, carentes de virtudes - julgando-se humanamente inferiores. (ELIAS, 2000, p. 19).

Dentro dessa figuração, formada por dois grupos interdependentes, percebemos as estigmatizações produzidas pelo grupo estabelecido em relação à condição de irmãs de bolsa. Para que isso diminua é necessário que elas se submetam às normas especificas do grupo do qual querem fazer parte. "Esse preço tem que ser individualmente pago por cada um de seus membros, através da sujeição de sua conduta a padrões específicos de controle dos afetos" (ELIAS, 2000, p. 26).

Dessa maneira, ao final do período de avaliação a noviça pode ser aceita ou não na Irmandade da Boa Morte, vai depender da sua conduta, do respeito à instituição e a obediência ao estatuto.

Elas [as irmãs mais antigas] não chamam a atenção, a gente pode ir, pode isso, pode aquilo. Porque você esta passando por uma avaliação. Importante é sentir verdade. Quem é essa que está ingressando? Como também muitas que foram apresentadas não ficaram. É por isso que eu falo, não é difícil entrar no candomblé, difícil é naquela irmandade. Ela tem um estatuto muito rigoroso. (DONA NENEU, 2017).

Ao ser aceita na Irmandade, a nova membra recebe a beca, joias e a permissão para participar de todos os rituais. "A solidariedade entre as irmãs é bem marcante, pois todas se unem, doando joias para a nova irmã, auxiliando na confecção das roupas utilizadas pela nova integrante nos dias festivos". (MACHADO, 2013, p. 47).

Dentro da instituição e para a festa as irmãs se organizam a partir dos cargos de juíza perpétua, provedora, procuradora geral, tesoureira e escrivã. Segundo a 
tradição, a eleição se dava através de grãos de feijão e milho para a escolha dos cargos de Provedora, Procuradora Geral, Tesoureira e Escrivã.

Juíza Perpétua: Irmã com mais tempo na irmandade. Guarda os segredos da irmandade, é a conselheira do grupo para todas as questões pertinentes a irmandade e para além desta. Zela pela conduta de todas as irmãs.

Provedora: Ocupa-se dos preparativos da festa; da arrumação da roupa de Nossa Senhora e da igreja; confecção dos convites e organização nas irmãs nos dias da esmola; agenda a missa na paróquia.

Procuradora Geral: Auxilia a provedora na organização da festa, é seu o papel de levar a santinha, para a casa da provedora.

Tesoureira: Administra os recursos financeiros.

Escrivã: Auxilia na ornamentação da festa e na produção das velas, além de registrar em ata todos os acontecimentos ocorridos durante a festa. (MACHADO, 2013, p. 50).

Antes da festa de Nossa Senhora da Boa Morte, que acontece anualmente de 13 a 17 de agosto, ocorre duas cerimônias importantes: a eleição da comissão de festa do ano seguinte e, uma semana depois, a chamada "esmola geral". A primeira impossibilita a concentração de poder, e a segunda, é o momento que as irmãs saem pelas principais ruas de Cachoeira, portando sacolas vermelhas, bordadas com o símbolo da irmandade, pedindo ajuda para a festa nas casas, comércio e feira livre.

No primeiro dia de festa as irmãs se confessam na sede da irmandade a tarde. À noite vão em direção a Capela de Nossa Senhora D’Ajuda, onde rezam e incensam o ambiente em torno da imagem de Nossa Senhora morta. Nesse dia estão todas vestidas de branco e saem com velas em procissão com a imagem da santa num andor em direção a Igreja Matriz (Igreja Nossa Senhora do Rosário), fazendo uma parada em frente à Casa Estrela. Na igreja colocam a imagem de Nossa Senhora em frente ao altar e louvam a Maria. "Essa missa é para as irmãs falecidas, momento que lembram seus nomes, louvando suas memórias." (BARBOSA, 2011, p. 58).

No segundo dia acontece o enterro simbólico. Com a imagem de Nossa Senhora da Boa Morte na igreja as irmãs saem da sede em procissão noturna com velas e vestidas com a beca (saia preta, blusa branca, lenço branco na cintura), exceto as irmãs de bolsa que se vestem de branco todos os dias. "Ao chegarem à igreja as irmãs se encontram com a santa morta, tiram o véu que cobre seu rosto, acariciando-a; seus atos expressam tristeza.” (BARBOSA, 2011, p. 59). A finalização 
da cerimônia acontece com as irmãs em volta da imagem incensada pelo padre e com a procissão de Nossa Senhora acompanhada pelas filarmônicas da cidade, percorrendo as principais ruas de Cachoeira e recolhendo-se na capela de Nossa Senhora da Boa Morte ${ }^{10}$.

O dia 15 de agosto é o terceiro dia de festa, o dia da Assunção de Nossa Senhora da Glória. A procissão sai pela manhã da sede da irmandade acompanhada pelas filarmônicas em direção à Igreja Matriz. Da igreja seguem pelas ruas da cidade e retornam a sede, onde deixam à santa. De lá se dirigem novamente a Igreja Matriz, onde acontece a transferência dos cargos e posse da nova comissão para a festa do ano seguinte. Nesse dia as irmãs carregam o andor (auxiliadas por alguns homens) e levam flores, jogando-as sobre a imagem de Nossa Senhora, que é louvada com palmas pelos fiéis presentes.

As irmãs comemoram a Assunção de Nossa Senhora adornadas com correntes e colares que lembram a faustosa pompa das antigas negras do partido alto. Vestidas com a farda/beca, só que com o pano da costa do lado vermelho (traje de gala), exprimem a alegria que sentem com a elevação de Nossa Senhora aos céus e com a liberdade da escravidão. (BARBOSA, 2011, p. 59).

Nesse dia, após os rituais sagrados, as irmãs se reúnem na sede da irmandade e oferecem um almoço para convidados e pessoas da comunidade, acompanhado de valsa e samba de roda no Largo D’ajuda.

Os dias 16 e 17 não apresentam caráter religioso. No dia 16 de agosto elas preparam e oferecem um cozido e no dia 17 oferecem um caruru, ambos acompanhados por samba de roda no Largo D'ajuda. "O ato de dar comida equivale, para as irmãs, a abundância e prosperidade.” (BARBOSA, 2011, p. 63).

A festa de Nossa Senhora da Boa Morte é um momento importante da materialização do sincretismo religioso. Nela podemos visualizar mulheres negras, vinculadas a religiões de matriz africana em comunhão com elementos da igreja católica, mantendo e propagando suas tradições e crenças. Além de proporcionar também a ligação entre o sagrado e o profano.

${ }^{10}$ Nos dois primeiros dias de festa as irmãs portam-se em procissão tal como num velório. 
Para finalizar este tópico, para além da festa, é preciso pensar na Irmandade em si. Uma instituição que está intrinsecamente ligada à vida e à morte através de seus símbolos (cajado, brasão), de suas vestimentas, comidas e rituais que fazem menção a essa passagem espiritual. Uma instituição religiosa secularizada que representa a resistência da mulher negra.

\section{Práticas educativas na Irmandade da Boa Morte}

Para analisar as práticas educativas na Irmandade da Boa Morte utilizaremos a metodologia da história oral a partir das contribuições de Ferreira e Amado (2006), que discutem o status da história oral a partir de três dimensões: a história oral com metodologia, como técnica e como disciplina. Como técnica ela não passa de um conjunto de procedimentos técnicos para utilização do gravador em pesquisa e posterior conservação das fitas; como disciplina inaugurou técnicas específicas de pesquisa e um conjunto próprio de conceitos, o que lhe confere significado e dá unidade ao campo; como metodologia, reconhecem a história oral como uma área de estudos com objeto próprio e capacidade de gerar soluções teóricas.

Procedemos então com a realização de entrevistas ${ }^{11}$ com três irmãs: Adenildes Ferreira Lemos (71 anos, conhecida como Dona Belinha, há aproximadamente 23 anos na irmandade), Dalva Damiana de Freitas (90 anos, participa da irmandade há aproximadamente 67 anos) e Neci Santos Leite (59 anos, conhecida como Dona Neneu, há aproximadamente 17 anos na irmandade). Segundo Paul Thompson (1992, p. 258), “o objetivo de uma entrevista deve ser revelar as fontes do viés, fundamentais para a compreensão social, mais do que pretender que elas possam ser aniquiladas por um entrevistador desumanizado 'sem um rosto que exprima sentimentos"”.

Tendo em vista que todo ensinamento dentro da Irmandade é transmitido de forma oral, indagamos como ocorre essa prática.

\footnotetext{
11 Utilizamos o mesmo roteiro de entrevista com as três depoentes e todas assinaram o termo de cessão concordando com o uso das entrevistas para fins acadêmicos.
} 
As mais antigas sabe mais do que as que tão chegando, né? Aí passa pra quem tá iniciando. (DONA BELINHA, 2017).

A passagem [dos ensinamentos] é feita pelas irmãs mais velhas, vão ensinando a nós, mais novas. A gente tem que ter uma obediência rigorosa. [...] ali é doutrina, é disciplina e a gente tem que aprender, pra outras que vem entrando a gente poder ensinar. (DONA NENEU, 2017).

Insistimos nessa questão e perguntamos se existe algum documento ou livro no qual esteja registrado esses ensinamentos, ao que elas respondem negativamente:

Eu The digo, as irmãs não dão o fundamento da Irmandade a ninguém, porque não pode. $\mathrm{Na}$ época as escravas não sabiam ler nem escrever, então é na oralidade até hoje. E o interesse para você aprender, você tem que dar sua dedicação ao máximo que elas não se omitem a ensinar. Agora, é do seu interesse querer aprender [...] mas o segredo é a oralidade, é por isso que ali vem passando de geração em geração, de uma para outra, como se diz: de mãe pra filha. (DONA NENEU, 2017).

A partir do que foi dito pelas entrevistadas percebemos que cabe a cada noviça a dedicação e o interesse em aprender os ensinamentos da irmandade. Destarte, verificamos que há uma preocupação em relação à conduta e comportamento das irmãs de bolsa, tanto dentro, como fora da instituição, conforme demonstramos no tópico anterior em relação ao período de avaliação a qual são submetidas.

Desde que entramos na Irmandade temos que ter uma vida social mais regrada, de cair em bebedeira e essas coisas todas não pode, não é pra acontecer isso, pelo respeito que nós ganhamos. (DONA BELINHA, 2017).

É observada principalmente as que estão entrando agora, novatas. São observadas porque é uma irmandade. Essa irmandade é observada e exige respeito. (DONA DALVA, 2017)

Por fim, quando indagadas sobre os motivos que as levaram a participar da irmandade e se gostam de fazer parte dela, percebemos a forte presença de questões culturais, de identidade, de solidariedade e de resistência.

O amor a Maria. Aquela emoção da irmandade mesmo, das nossas raízes, isso me influenciou. (DONA BELINHA, 2017). 
É uma felicidade que nós temos quando estamos na casa da Boa Morte, é felicidade. A Boa Morte é respeito, é ter amor a Nossa Senhora, amor às próprias irmãs, união. É dando que se recebe foi assim que saímos do cativeiro. (DONA DALVA, 2017).

Somos mulheres negras, uma irmandade que foi nascida dentro de uma senzala e tá até hoje na resistência. (DONA NENEU, 2017).

\section{Considerações finais}

Por se tratar de uma irmandade religiosa, percebemos a existência de práticas educativas não escolares, no dizer de Gohn (2010), uma educação informal. Porém observamos que as irmãs mais antigas exercem sob as mais novas uma grande influência no tocante a transmissão das tradições e rituais próprios da instituição. Fato que gera uma tensão entre os dois grupos e provoca uma situação de anomia.

Compreendendo que o conceito de educação engendra modos de vida, ele se aproxima, assim, do conceito de cultura. Com isso, podemos constatar através dos depoimentos que a Irmandade da Boa Morte é um local onde se desenvolvem práticas educativas, ainda que estas estejam enraizadas em aspectos extremamente conservadores e tradicionais, tais como a disciplina e a obediência.

Apesar dos trabalhos já publicados e das entrevistas já realizadas, percebemos que existe um limite, no qual, nós pesquisadores, não podemos ultrapassar. Um limite que diz respeito aos conhecimentos próprios do grupo e que elas fazem questão de manter em segredo, em respeito aos seus antepassados e suas tradições.

\section{Referências}

AMADO, J.; FERREIRA, M. de M. Usos \& abusos da história oral. 8. ed. Rio de Janeiro: FGV, 2006.

AVÉ-LALLEMANT, R. Viagem pelo Norte do Brasil. Rio de Janeiro: Instituto Nacional do Livro, V. 1, 1961.

BAHIA. Governo do Estado. Secretaria de Cultura. IPAC. Festa da Boa Morte. Salvador: Fundação Pedro Calmon. 2011.

BARBOSA, M. S. Irmandade de Nossa Senhora da Boa Morte: Entre o Aiyê e o Orum. In: BAHIA. Secretaria de Cultura. IPAC. Festa da Boa Morte. Salvador: Fundação Pedro Calmon. 2011.

BRANDÃO, C. R. O que é educação. 40. reimpr. São Paulo: Brasiliense, 2001. 
ELIAS, N.; SCOTSON, J. L. Os estabelecidos e os outsiders. Sociologia das relações de poder a partir de uma pequena comunidade. Rio de Janeiro: Zahar, 2000.

FONSECA, T. N. de L. e. Letras, ofícios e bons costumes: civilidade, ordem e sociabilidade na América portuguesa. Belo Horizonte: Autêntica, 2009.

GOHN, M. da G. Educação não formal e o educador social: atuação no desenvolvimento de projetos sociais. São Paulo: Cortez, 2010.

GONÇALVES, L. A. O. Negros e a educação no Brasil. In: LOPES, E. M. T.; FARIA FILHO, L. M.; VEIGA, C. G. (org.). 500 anos de educação no Brasil. Belo Horizonte: Autêntica, 2000.

GUERRA FILHO, S. A. D. O povo e a guerra: participação popular nas lutas pela Independência na Bahia. Dissertação (Mestrado em História) - Universidade Federal da Bahia, UFBA, Salvador, 2004.

LE GOFF, J. História. In: LE GOFF, J. História e Memória. 5. ed. Campinas: Unicamp, 2003.

MACHADO, L. V. N. Poder feminino e identidade na Irmandade da Boa Morte. 2013. Dissertação (Mestrado) - Centro de Artes, Humanidades e Letras da Universidade Federal do Recôncavo da Bahia, UFRB, Cachoeira, 2013.

REIS, J. J. A morte é uma festa: ritos fúnebres e revolta popular no Brasil do século XIX. São Paulo: Companhia das Letras, 1991.

SANTANA, D. de J. Memória, tradição e oralidade: aspectos educacionais na Irmandade da Boa Morte. 2018. Trabalho de Conclusão de Curso (Graduação em História) Universidade Federal do Recôncavo da Bahia, UFRB, Cachoeira, 2018.

THOMPSON, P. A voz do passado: História Oral. Rio de Janeiro: Paz e Terra, 1992.

\section{Entrevistas}

DONA NENEU. [Entrevista cedida a] Djalma de Jesus Santana. dez. 2017.

DONA BELINHA. [Entrevista cedida a] Djalma de Jesus Santana. jul. 2017.

DONA DALVA. [Entrevista cedida a] Djalma de Jesus Santana. set. 2017.

RECEBIDO: $16 / 09 / 2019$

APROVADO: 16/10/2019
RECEIVED: 09/16/2019

APPROVED: $10 / 16 / 2019$
RECIBIDO: $16 / 09 / 2019$

APROBADO: $16 / 10 / 2019$ 